\title{
The aldA gene of Escherichia coli is under the control of at least three transcriptional regulators
}

\author{
Ana Limón, Elena Hidalgoł and Juan Aguilar \\ Author for correspondence: Juan Aguilar. Tel: +34 3402 4521. Fax: +34 34021896. \\ e-mail : Jaguilar@Farmacia.far.ub.es
}

Department of

Biochemistry, Faculty of Pharmacy, University of Barcelona, Diagonal 643, 08028 Barcelona, Spain

\begin{abstract}
Expression studies on the aldA gene encoding aldehyde dehydrogenase in Escherichia coli showed induction by two types of molecule (hydroxyaldehydes and 2-oxoglutarate), carbon catabolite repression and respiration dependence. Promoter deletion analysis showed that the proximal operator, which includes inducer-regulator complex and catabolite repression protein (Crp) recognition sites, was necessary for induction by either type of inducer, and that full induction by aldehydes required the cooperation of distal operator sequences beyond position -119. Interactions of the regulator protein with the -59 to -6 fragment were shown by DNA mobility shift assays. Fusions of different deletions of the aldA promoter to lacZ indicated that a Crp site proximal to the transcriptional start point (tsp) was functional in the cAMP-dependent catabolite repression of this system, whereas a distal control site was likely to operate in a cAMP-independent catabolite repression. DNA mobility shift and footprint analyses showed that only the tsp proximal site was bound by pure Crp with a $K_{d}$ of $5.4 \times 10^{-7} \mathrm{M}$. As shown by an Arc-defective strain, the aldA gene seems to be repressed by the Arc system under anaerobiosis, displaying its physiological full induction and activity in the presence of oxygen.
\end{abstract}

Keywords: aldehyde dehydrogenase, aldA, regulation, transcription, Escherichia coli

\section{INTRODUCTION}

The gene ald $A$ maps at min 32 (Baldomà \& Aguilar, 1988; Chen et al., 1987) of the Escherichia coli chromosome, and has been reported to encode an aldehyde dehydrogenase (ALDH) of 479 amino acids (Hidalgo et al., 1991) functioning on a broad spectrum of substrates. Initially it was assigned the role of oxidizing to L-lactate the L-lactaldehyde (Sridhara \& Wu, 1969) formed in the metabolism of L-fucose (Cocks et al., 1974) and Lrhamnose (Baldomà \& Aguilar, 1987). Further studies demonstrated that it was also involved in the oxidation of glycolaldehyde formed in the metabolism of different

\footnotetext{
†Present address: Department of Molecular and Cellular Toxicology, Harvard School of Public Health, 665 Huntington Ave, Boston, MA 02115, USA.

Abbreviations: ALDH, aldehyde dehydrogenase; Crp, catabolite repression protein; IHF, integration host factor; tsp, transcriptional start point. The GenBank accession numbers for the +45 to -156 and -157 to -185 sequences reported in this paper are M64541 and L09068, respectively.
}

pentoses (LeBlanc \& Mortlock, 1971) and in the metabolism of ethylene glycol in mutant cells adapted to grow on this non-natural carbon source (Boronat et al., 1983). In fact, it was shown that the enzyme oxidized other hydroxyaldehydes, including L-glyceraldehyde and the $\alpha$-oxoaldehyde methylglyoxal (Baldomà \& Aguilar, 1987).

The ALDH activity is induced not only by growth on $\mathrm{L}^{-}$ fucose, L-rhamnose or D-arabinose, through the formation of intermediate hydroxyaldehydes, but also by growth in the presence of glutamate or amino acids yielding glutamate, with the exception of proline (Quintillá et al., 1991). Induction by these amino acids requires glutamate accumulation. 4-Aminobutyric acid is also able to induce ALDH through its transamination to glutamate. Glutamate induction was shown to be due to its conversion to 2-oxoglutarate, the tricarboxylic acid cycle intermediate with which glutamate is in equilibrium. Consistently with that, growth on 2oxoglutarate also induces the ald $A$ gene. Both types of inducer, aldehydes and 2-oxoglutarate, share the same 
regulatory protein (Quintillá et al., 1991), so far uncharacterized, whose gene has not yet been located. Induction by either of these two compounds, which occurs only aerobically, is repressed by glucose. This catabolite repression is only partially relieved by cAMP, in accordance with the presence of an additional cAMPindependent catabolite repression by carbon sources other than glucose, such as glycerol (Quintillá et al., 1991). Thus the information available indicates that this enzyme is rather non-specific, participates in several metabolic pathways, and responds to multiple regulatory signals.

In this report, we analyse the control of expression of the ald $A$ gene and characterize three different regulatory functions in its promoter: one controlled by the regulator-inducer complex, another by the catabolite repression protein (Crp)-cAMP complex, and the third by the Arc anaerobic repressor.

\section{METHODS}

Bacterial strains and plasmids. The bacterial strains and plasmids used in this study are listed in Table 1.

Growth conditions and preparation of cell extracts. Cells were grown aerobically on LB or minimal medium as described previously (Boronat \& Aguilar, 1979). For growth on minimal medium, carbon sources were added to a basal inorganic medium in the following concentrations: glucose, $10 \mathrm{mM}$; L-rhamnose, $10 \mathrm{mM}$; glycerol, $20 \mathrm{mM}$; casein acid hydrolysate, $0.5 \%(\mathrm{w} / \mathrm{v})$. Anaerobically, carbon sources were added to minimal medium at double concentration. When necessary, the following antibiotics were added to the medium at the concentrations indicated: chloramphenicol, $30 \mu \mathrm{g} \mathrm{ml}^{-1}$; ampicillin, $100 \mu \mathrm{g} \mathrm{ml}^{-1}$; kanamycin, $25 \mu \mathrm{g} \mathrm{ml}^{-1}$; streptomycin, $30 \mu \mathrm{g} \mathrm{ml}^{-1}$; and tetracycline, $12.5 \mu \mathrm{g} \mathrm{ml}^{-1}$. Isopropyl $\beta$-Dthiogalactoside and 5-bromo-4-chloro-3-indolyl $\beta$-D-galactoside (X-Gal) were used at $10 \mu \mathrm{g} \mathrm{ml}^{-1}$ and $30 \mu \mathrm{g} \mathrm{ml}^{-1}$, respectively.

For the enzyme assays, the cells were harvested at the end of the exponential phase and the cell extract was prepared as described previously (Boronat \& Aguilar, 1981) in $10 \mathrm{mM}$ Tris/ $\mathrm{HCl}$ buffer ( $\mathrm{pH} 7 \cdot 0$ ). For DNA mobility shift assays, cells were harvested at the end of the exponential phase by centrifugation and subsequently resuspended in lysis buffer containing $100 \mathrm{mM}$ potassium phosphate ( $\mathrm{pH} 7 \cdot 4), 50 \mathrm{mM}$ $\mathrm{KCl}, 1 \mathrm{mM}$ EDTA, $10 \%$ (w/v) glycerol, $1 \mathrm{mM}$ dithiothreitol and $160 \mu \mathrm{g}$ phenylmethylsulfonyl fluoride $\mathrm{ml}^{-1}$. Cell debris was removed by centrifugation at $10000 \mathrm{~g}$ for $20 \mathrm{~min}$. The supernatant fractions were stored in $30 \%(\mathrm{w} / \mathrm{v})$ glycerol at $-80^{\circ} \mathrm{C}$.

Enzyme assays. The ALDH activity was assayed spectrophotometrically (at $340 \mathrm{~nm}$; Shimadzu UV-240 spectrophotometer) by monitoring the increased rate of NADH formation at $25^{\circ} \mathrm{C}$. Since this enzyme was also reported to be responsible for the conversion of glycolaldehyde to glycolate (Caballero et al., 1983), glycolaldehyde was routinely used instead of lactaldehyde because of the commercial unavailability of lactaldehyde. The assay mixture $(1 \mathrm{ml})$ consisted of $1 \mathrm{mM}$ lactaldehyde or glycolaldehyde, $100 \mathrm{mM}$ sodium glycine buffer ( $\mathrm{pH} 9.5$ ) and $2.5 \mathrm{mM}$ NAD. One unit of ALDH activity transformed $1 \mu \mathrm{mol}$ substrate $\mathrm{min}^{-1}(\mathrm{mg} \text { protein })^{-1}$.

The $\beta$-galactosidase activity in strains grown under specified conditions was assayed as described by Miller (1992) and the values are reported in the units defined by that author.

The recorded enzyme activities are the means of at least three independent cultures; the overall variation was not greater than $15 \%$.

The protein concentration in cell extracts was determined by the method of Lowry with bovine serum albumin as the standard.

DNA manipulation and genetic techniques. Plasmid DNA was routinely prepared by the boiling method (Holmes \& Quigley, 1981). For large-scale preparation, a crude DNA sample was subjected to purification on a column (Qiagen). DNA manipulations were performed essentially as described by Sambrook et al. (1989). The DNA sequence was determined by using the dideoxy chain-termination procedure of Sanger $e t$ al. (1977), with double-stranded plasmid as the template.

Deletions of plasmid pALD1.1 (Hidalgo et al., 1991) were generated by using the Promega exonuclease III/S1 nuclease system. The plasmid was linearized by digestion with SacI

Table 1. E. coli strains used in this work

\begin{tabular}{|c|c|c|}
\hline Strain & Relevant genotype & Source/reference \\
\hline ECL1 & $\mathrm{HfrC}$ phoA8 relA1 tonA22 $\mathrm{T}^{\mathrm{R}}(\lambda)$ & $\operatorname{Lin}(1976)$ \\
\hline $\mathrm{DH} 5 \alpha \mathrm{F}^{\prime}$ & $\begin{array}{l}\phi 80 \mathrm{~d} l a c Z \Delta \mathrm{M} 15 \Delta(\operatorname{lac} Z Y A-\arg F) \mathrm{J} 169 h s d R 17\left(\mathrm{r}_{\mathrm{K}}^{-} \mathrm{m}_{\mathrm{K}}^{+}\right) \operatorname{supE} 44 \lambda^{-} \text {recA1 endA1 } \\
\text { gyrA96 thi-1 relA1 }\end{array}$ & BRL \\
\hline MC1061 & hsdR mcrB araD139 $\Delta($ araABC-leu $) 7679 \Delta l a c X 74$ galU galK rpsL thi & Meissner et al. (1987) \\
\hline RYC1000 & $\operatorname{araD139} \Delta($ lacIPOZYA) U169 rpsL (str) thi mot recA59 & $\begin{array}{l}\text { M. Aldea, University of } \\
\text { Lleida, Spain }\end{array}$ \\
\hline JA111 & ECL40 recA1 srlA:: $\operatorname{Tn} 10$ & Hidalgo et al. (1991) \\
\hline ECL547 & $\begin{array}{l}\mathrm{F}^{-} \text {araD139 } \Delta(\arg F-l a c) \text { U169 rpsL150 relA1 fib-5301 ptsF25 deoC1 } \Delta f r d-101 s d b^{+} \\
\phi(s d h-l a c)\end{array}$ & Iuchi \& Lin $(1988)$ \\
\hline ECL968 & ECL547 arcA131 & Iuchi \& $\mathrm{Lin}(1992)$ \\
\hline K37 & $\operatorname{str} A \mathrm{gal} / \mathrm{K} 2 \mathrm{su}{ }^{\mathrm{o}} \lambda^{-} \mathrm{F}^{-}$ & H. Nash \\
\hline HN1491 & $\mathrm{K} 37 \operatorname{bim} A:: c a t$ & Granston \& Nash (1993) \\
\hline K2704 & $\mathrm{K} 37$ himD $3:$ :cat & Mozola \& Friedman (1985) \\
\hline
\end{tabular}


restriction enzyme and then a $5^{\prime}$-overhanging end was formed by digestion with EcoRI (see Fig. 1). In this way, the $3^{\prime}$-end of the linear DNA was protected from digestion by the deletion system, while the $5^{\prime}$-end marked the direction of progress of the different deletions. Deletions were converted to blunt ends, ligated to plasmid Bluescript and their extension was verified by nucleotide sequencing.

Transcriptional fusions were constructed by inserting the DNA fragments into plasmid pRS550, as described by Simons et al. (1987). The plasmids containing the desired deletion were digested with PvuII and the resulting inserts (from 400 to $700 \mathrm{bp}$ ) were purified. The vector pRS550 was linearized by digestion with $B a m \mathrm{HI}$, blunted by treatment with Klenow polymerase and ligated with the inserts by T4 ligase. The direction of the inserts and their junctions were verified by nucleotide sequencing. Plasmid pRS550 carries a cryptic lac operon and genes that confer resistance to both kanamycin and ampicillin. After introduction of the recombinant plasmid into the streptomycin-resistant strain MC1061, blue colonies were isolated on $\mathrm{X}-\mathrm{Gal}$ plates containing ampicillin, kanamycin and streptomycin. Single-copy fusions were obtained by transferring the plasmid fusions into $\lambda \mathrm{RS} 45$ and then introduced to strain RYC 1000 as previously described by Simons et al. (1987).

RNA preparations and Northern blot experiments. For preparation of total RNA, cells of a $25 \mathrm{ml}$ culture grown to $\mathrm{OD}_{650} 0.5$ were collected by centrifugation at $5000 \mathrm{~g}$ for $10 \mathrm{~min}$ and processed as described by Belasco et al. (1985). Northern blot hybridization was performed with each RNA sample $(10 \mu \mathrm{g})$ following the procedure described previously by Moralejo et al. (1993). The probe was ${ }^{32} \mathrm{P}$-labelled by the random primed method (Sambrook et al., 1989) using as template a $500 \mathrm{bp}(P s t \mathrm{I}-\mathrm{Bam} \mathrm{HI})$ ald A internal fragment (see Hidalgo et al., 1991).

DNA mobility shift assay. We adopted the method described by Nunoshiba et al. (1992) with minor modifications for the DNA mobility shift assay. The DNA fragments were endlabelled by filling in with the Klenow fragment of DNA polymerase $I$ and $\left[\alpha^{3}{ }^{32} \mathrm{P}\right] \mathrm{dATP}$. For the DNA-binding reaction, mixtures $(20 \mu \mathrm{l})$ contained $10 \mathrm{mM}$ Tris $/ \mathrm{HCl}(\mathrm{pH} 7 \cdot 5), 75 \mathrm{mM}$ $\mathrm{KCl}, 2 \mathrm{mM}$ dithiothreitol, $10 \%(\mathrm{w} / \mathrm{v})$ glycerol, $2 \mu \mathrm{g}$ poly $(\mathrm{dI}-$ $\mathrm{dC}), 10 \mathrm{fmol}$ labelled fragments and protein extracts, purified Crp protein (a gift from S. Adhya, NIH, USA) and/or RNA polymerase from $E$. coli (purchased from Pharmacia and diluted in reaction buffer with $1 \mathrm{mM} \mathrm{Mg}^{2+}$ ) in the amounts indicated in the experiments. The binding reactions were performed at $25^{\circ} \mathrm{C}$ for $15 \mathrm{~min}$ and samples were electrophoresed in $5 \%(\mathrm{w} / \mathrm{v})$ polyacrylamide gels in running buffer (20 mM Tris/ $\mathrm{HCl}, \mathrm{pH} \mathrm{8.0;3} \mathrm{mM} \mathrm{sodium} \mathrm{acetate,} \mathrm{pH} 7.9$; $1 \mathrm{mM}$ EDTA) at $4{ }^{\circ} \mathrm{C}$. After being run for $4 \mathrm{~h}$ at $200 \mathrm{~V}$, the gels were dried under vacuum and the bands were visualized by autoradiography.

The integration host factor (IHF)-DNA gel mobility shift assays were carried out essentially as described by Wu \& Datta (1992). In this case, labelled fragments were incubated with purified IHF (a gift from H. A. Nash, NIH, USA, who suggested that it always be diluted in the presence of $100 \mathrm{mM}$ $\mathrm{KCl}$ and $2 \mathrm{mg}$ bovine serum albumin $\mathrm{ml}^{-1}$ ) in $25 \mu \mathrm{l}$ reaction

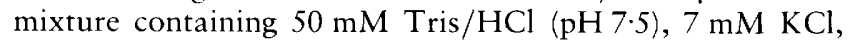
$1.1 \mathrm{mM}$ EDTA, $1 \mathrm{mM}$ dithiothreitol, $7 \mathrm{mM} \mathrm{MgCl}_{2}, 3 \mathrm{mM}$ $\mathrm{CaCl}_{2}, 10 \%(\mathrm{w} / \mathrm{v})$ glycerol, $200 \mu \mathrm{g}$ nuclease-free bovine serum albumin ( $\mathrm{ml}$ reaction mixture $)^{-1}$ and $2 \mu$ g denatured, sonicated salmon sperm DNA. Incubations were carried out at $25^{\circ} \mathrm{C}$ for $15 \mathrm{~min}$ and samples were electrophoresed in a $4 \%(\mathrm{w} / \mathrm{v})$ native polyacrylamide gel in running buffer $(450 \mathrm{mM}$ Tris; $450 \mathrm{mM}$ boric acid, $\mathrm{pH} 8 \cdot 3 ; 1 \mathrm{mM}$ EDTA) for $1-2 \mathrm{~h}$ at $350 \mathrm{~V}$.

DNase I footprinting. Fragment 2 (Fig. 3) was PCR-amplified using as template plasmid Bluescript in which fragment 2 had been previously cloned (pBS-f2); as primers T3 and T7 oligonucleotides, one of which had been labelled at the $5^{\prime}$-end with $\left[\gamma^{-32} \mathrm{P}\right] \mathrm{dATP}\left(1 \cdot 1 \times 10^{14} \mathrm{~Bq} \mathrm{mmol}{ }^{-1} ;\right.$ Amersham $)$; and T4 polynucleotide kinase. The PCR product was purified by nondenaturing PAGE and Elutip (Schleicher \& Schuell) columns. The Crp-DNA binding reactions were performed as described above. After incubation, $\mathrm{MgCl}_{2}$ and $\mathrm{CaCl}_{2}$ were added to final concentrations of $1.25 \mathrm{mM}$ and $5 \mathrm{mM}$, respectively. The mixtures were treated with DNase I $5 \mathrm{ng}$ DNase $\mu \mathrm{l}^{-1}$ (Sigma) in $50 \mathrm{mM}$ Tris $/ \mathrm{HCl}, \mathrm{pH} 7 \cdot 5,10 \mathrm{mM} \mathrm{MgSO}, 1 \mathrm{mM}$ dithiothreitol and $50 \%, \mathrm{w} / \mathrm{v}$, glycerol] at $25^{\circ} \mathrm{C}$ for $2 \mathrm{~min}$. The reactions were stopped by addition of $5 \mu \mathrm{g}$ yeast $\mathrm{tRNA} \mathrm{ml}^{-1}$ in $270 \mathrm{mM}$ ammonium acetate, $70 \%(\mathrm{v} / \mathrm{v})$ ethanol. After precipitation, the DNA pellet was resuspended in $5 \mu$ l formamide loading buffer (Sambrook et al., 1989) and the samples were subjected to electrophoresis through an $8 \%(\mathrm{w} / \mathrm{v})$ denaturing sequencing gel, drying and autoradiography.

\section{RESULTS}

\section{Physical mapping and sequence of the aldA promoter}

The physical map and sequence of a $1 \mathrm{~kb}$ fragment upstream of the ATG start codon of the aldA structural gene previously cloned and sequenced (Hidalgo et al., 1991) was determined. Fig. 1 displays the physical map of clone pALD1.1 encompassing this region, and part of its sequence, which includes 185 nucleotides upstream from the transcriptional start point (tsp; position 1) previously established by Hidalgo et al. (1991). Analysis of the sequence revealed several possible regulatory elements able to participate in the control of ald $A$ expression. A -10 hexamer (GTTAAT) was identified with four nucleotides matching the consensus and an extended TGN sequence directly upstream from these four nucleotides (Kumar et al., 1994), whereas no clear -35 box was apparent. Among the several inverted repeats with high energy of stabilization found, there was one centred at -60 with the Crp-specific recognition consensus described by de Crombrugghe $e t$ al. (1984), and another centred at -134 , which contains only the upstream half of the Crp consensus. Also an Arc consensus as described by Lynch \& Lin (1996) overlaps with the -10 hexamer. Finally, three IHF recognition consensus sequences (Nash \& Granston, 1991) were apparent at positions 7 to $-6,-55$ to -67 and -130 to -142 .

\section{Control of aldA gene expression is at the transcriptional level}

Total RNA was prepared from cells of the ALDHdeficient strain JA111 transformed with plasmid pALD1.1 or from strain ECL1 grown under inducing and non-inducing conditions and analysed by Northern blotting with an aldA internal labelled probe. The probe hybridized to a transcript of $1.5 \mathrm{~kb}$ when the RNA 


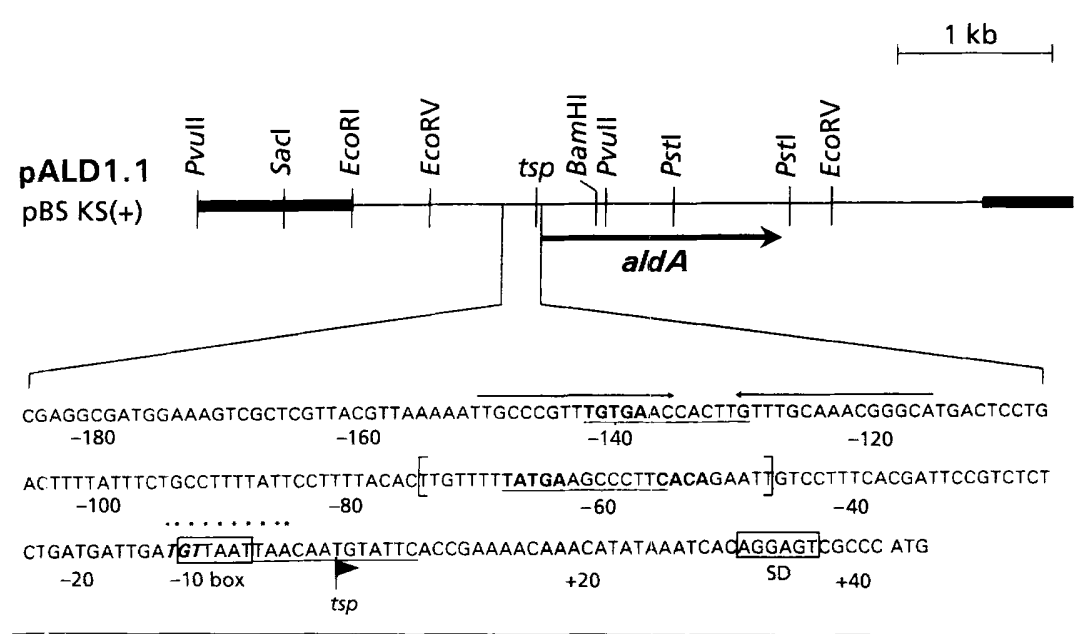

Fig. 1. Physical map of plasmid pALD1.1 with the restriction sites and the location of the ald $A$ open reading frame (thick arrow) in the insert (thin line) cloned in the vector Bluescript (thick line). The sequence of the promoter region between positions -185 and +45 is shown in the expansion below. The ATG initiation codon is at the $3^{\prime}$-end of the sequence, the Shine-Dalgarno (SD) ribosome recognition site is boxed and the tsp is shown by a black arrowhead. The inverted repeat of highest energy of stabilization is indicated by a thin arrow. The -10 box is labelled with the extended sequence in italics. The sequences matching the consensus for Crp are in bold, the extent of the Crp footprinting is between square brackets, the IHF sequences are underlined and the sequence matching the ArcAbinding consensus is shown by asterisks. Numbers indicate the nucleotide position, taking tsp as position +1

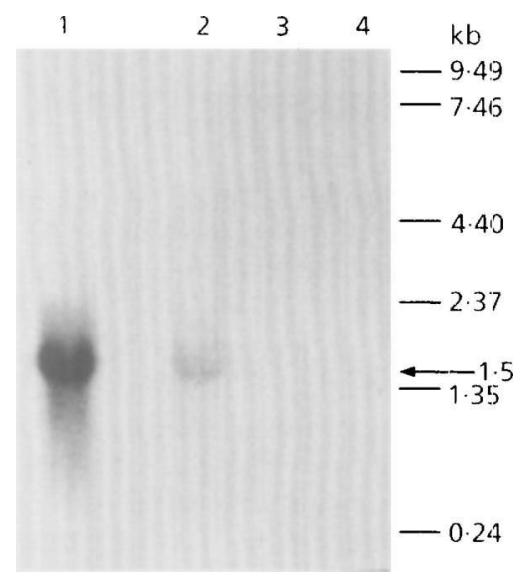

Fig. 2. Northern blots of total RNA from strain JA111 transformed with plasmid pALD1.1 grown aerobically on rhamnose (lane 1) or strain ECL1 grown aerobically on rhamnose (lane 2), anaerobically on rhamnose (lane 3), or aerobically on glucose (lane 4). Sizes of the transcripts in $\mathbf{k b}$ according to markers used in the experiment are indicated.

preparation was from cells of strain JA111(pALD1.1) (Fig. 2, lane 1) or strain ECL1 (Fig. 2, lane 2) grown aerobically on rhamnose. Hybridization was higher for strain JA111(pALD1.1) corresponding to a much higher expression from the plasmid-encoded ald $A$ gene and was in accord with measured ALDH activity: 7.0 $\mathrm{U} \mathrm{mg}^{-1}$ for strain JA111(pALD1.1) in contrast to $0 \cdot 3 \mathrm{U} \mathrm{mg}^{-1}$ for strain ECL1. No hybridization was detectable when cells of strain ECL1 were grown anaerobically on rhamnose or aerobically on glucose (Fig. 2, lanes 3-4). The size and the hybridization pattern agree with those predicted for an independent transcriptional unit containing only the aldA gene.

Since, as indicated by the Northern analysis, the differential expression of the aldA gene seemed to be regulated at the transcriptional level, several deletions of the promoter were made to study the sequences involved in the transcriptional regulation. The resulting plasmids named after their $3^{\prime}$ deletion end-points (Fig. 3) were introduced into strain JA111 to study aldA expression. A construction with a fragment deleted up to position +17 , and hence with the promoter totally deleted, was used as a negative control. Deletion studies included a construction with a fragment containing up to position -287 , which gave results equivalent to those of parental plasmid pALD1.1, which includes the complete promoter. This latter construction showed that the system was sensitive to inducing carbon sources such as rhamnose or casein acid hydrolysate, while growth on non-inducing carbon sources such as succinate or glycerol yielded low activities (data not shown). It was also seen that the system was under two negative regulatory mechanisms: catabolite repression, as indicated by the low activity when glucose or glycerol was added to a rhamnose culture; and anaerobic repression, as indicated by the absolute dependence of the enzyme activities on the presence of oxygen.

\section{Control of aldA gene expression by the activator}

Results presented in Fig. 3 showed that full induction by growth on rhamnose requires up to position -170 , while full induction by growth on casein acid hydrolysate requires sequence only to position - -93 , suggesting a different mechanism for each of the two inducing conditions. Constructions including sequences upstream of position -193 reduced the full induction by casein acid hydrolysate by $40 \%$, to values similar to those of wild-type ald A promoter function (pALD1.1). Expression of ald $A$ was completely abolished by anaerobiosis under all of the conditions tested. Finally, for all deletions, growth on rhamnose plus glucose led to loss of induction, while growth on rhamnose plus glycerol gave partial loss of the induction displayed by the deleted promoters containing the distal control region (up to position -170 ). The construction with the -93 


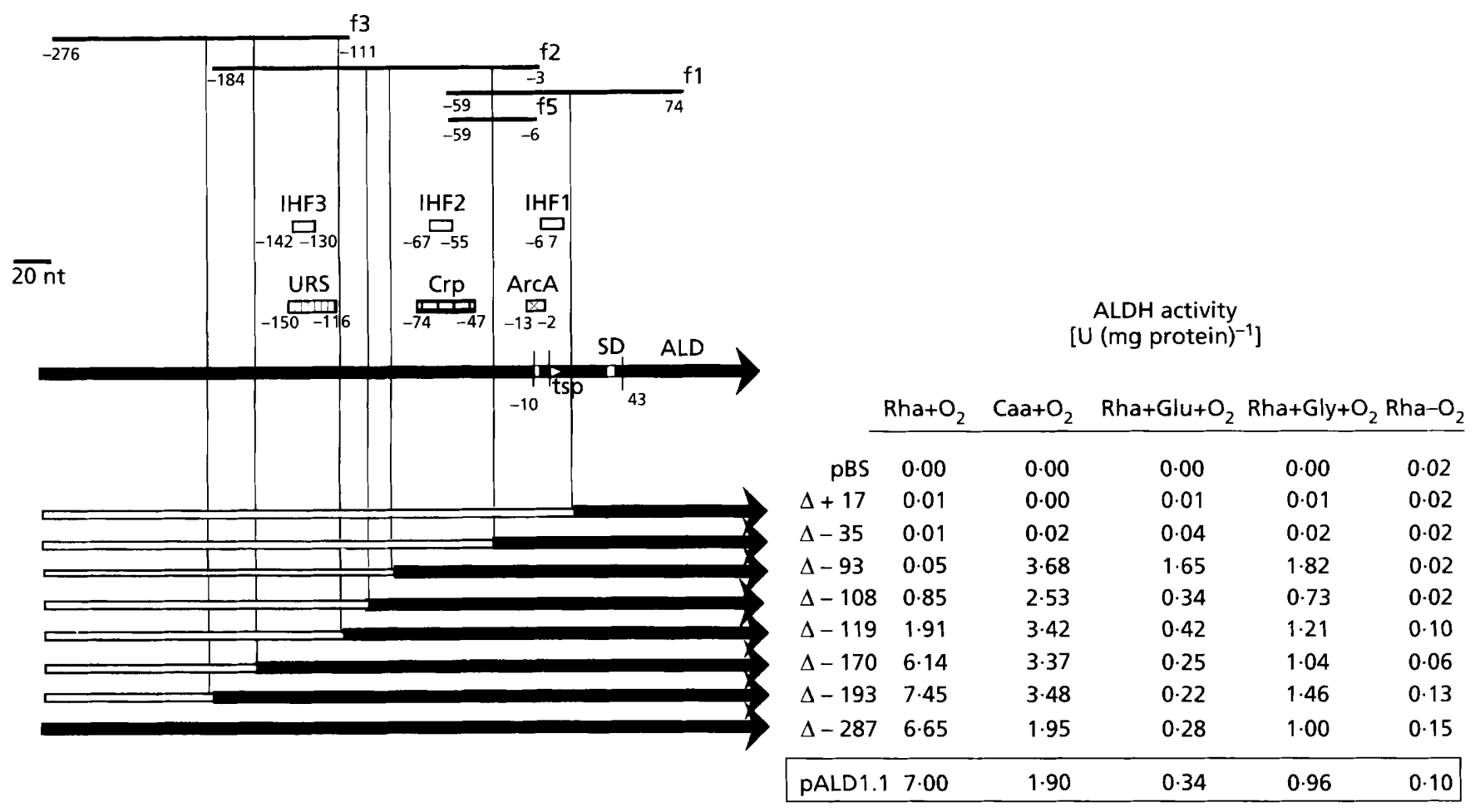

Fig. 3. Expression of the aldA gene from pALD1.1 and deletion analysis of the aldA promoter region. A graphic representation of the insert (thick line) cloned in the Bluescript vector (not shown) is presented in the middle part. tsp $(+1)$, the -10 box $(-10)$, the Shine-Dalgarno box (SD) and the translation initiation codon ATG (43) of the aldA structural gene (ALD) indicated by the arrow are marked on the insert. Putative binding sites for Crp, ArCA, IHF and the upstream regulatory site (URS), as well as fragments $f 1, f 2, f 3$ and $f 5$ used for retardation experiments, are presented in the upper part by boxes and lines with numbers indicating their limits. Deleted constructions of the promoter region that were cloned into the same vector and assayed for ALDH activity are shown below by solid arrows. Numbers next to these arrows indicate the $3^{\prime}$-end of the deleted DNA represented by the open bars. The specific ALDH activity associated with each construction is indicated on the right. ALDH activities were assayed from transformed cells grown under the following conditions: aerobically on rhamnose $\left(\mathrm{Rha}+\mathrm{O}_{2}\right)$, casein acid hydrolysate $\left(\mathrm{Caa}+\mathrm{O}_{2}\right)$, rhamnose plus glucose $\left(\mathrm{Rha}+\mathrm{Glu}+\mathrm{O}_{2}\right)$ and rhamnose plus glycerol $\left(\mathrm{Rha}+\mathrm{Gly}+\mathrm{O}_{2}\right)$, or anaerobically on rhamnose $\left(\mathrm{Rha}-\mathrm{O}_{2}\right)$. The bottom line displays the activities obtained with the entire insert contained in plasmid pALD1.1.

fragment, which is not inducible by rhamnose, presented some induction either by glycerol or glucose. The reason for this unexpected induction in this particular construction is unknown.

Binding of the activator protein to this sequence was proven by gel retardation experiments with ${ }^{32} \mathrm{P}$-labelled fragment 5 (see 55 in Fig. 3). The electrophoretic mobility of fragment 5 ( -6 to -59$)$ was retarded by crude extracts of cells of strain ECL1 grown aerobically on rhamnose (Fig. 4a). To determine the sequence specificity of binding, 100-fold excess of unlabelled DNA fragment was mixed as the competitor with the labelled fragment. The major retarded band was markedly reduced by addition of the unlabelled fragment. However, there was no competition by poly (dI-dC). Furthermore, the major band was found to be proportional to the concentration of protein in the binding reaction. The retarded band with lower mobility (band labelled $\mathrm{N}$ ) corresponded to RNA polymerase-fragment complex as indicated by the enhancement of this band upon addition of pure RNA polymerase to the mixture (not shown).
Binding of the regulator to the DNA fragment containing the ald $A$ control region was further characterized by gel retardation by studying the effect of addition of inducer molecules to extracts of cells grown under either inducing (rhamnose) or non-inducing (glucose) conditions (Fig. 4b). Extracts of glucose-grown cells displayed a retarded band (Fig. $4 b$, lane 3) due to endogenous 2-oxoglutarate formed in the metabolism. Addition of glycolaldehyde increased this major retarded band R, and revealed a fainter retarded band $G$, probably due to a multimeric complex (Fig. $4 \mathrm{~b}$, lanes 4 and 5). Addition of 2-oxoglutarate with or without glycolaldehyde strongly increased the same major retarded band R, but did not reveal the G band (Fig. 4b, lanes 6 and 7), presumably due to regulator capture in the R band.

\section{Crp-cAMP control of aldA gene expression}

To assess the putative function of the Crp site centred at -60 and that of the upstream regulatory site (URS in Fig. 3) centred at -134 , three deletions were fused to the 
(a)

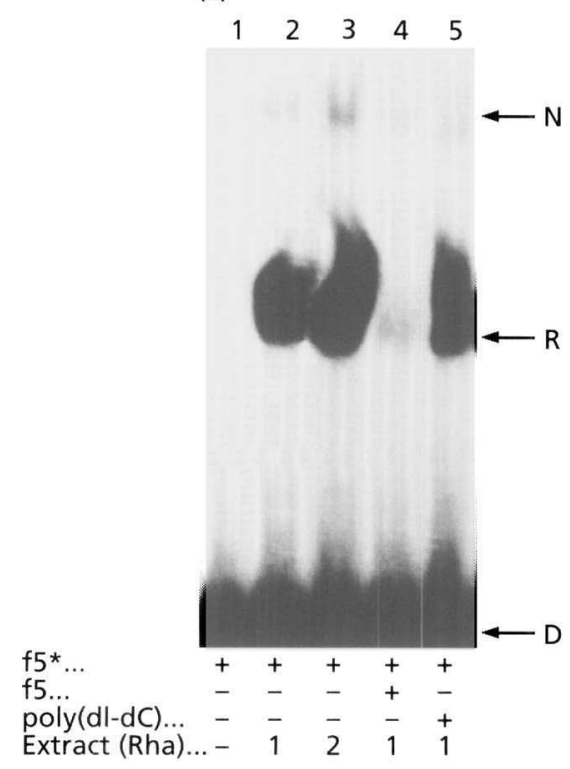

(b)

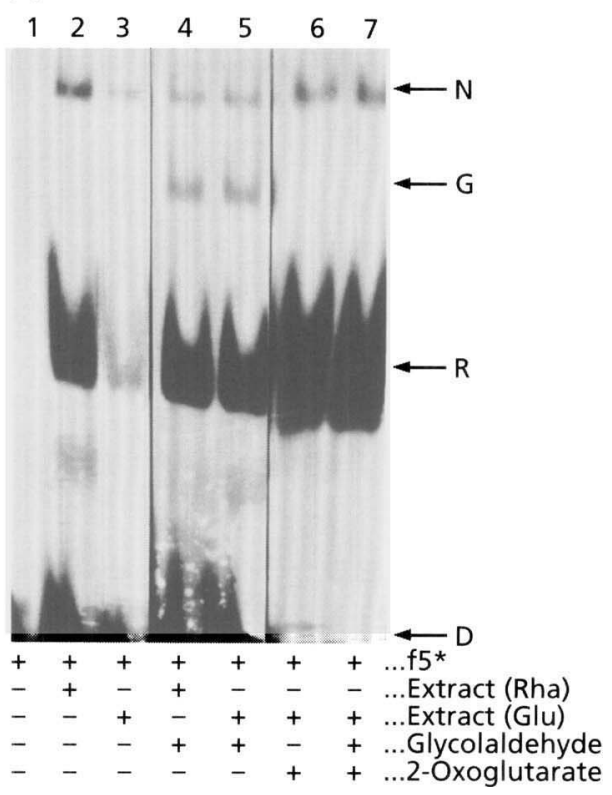

Fig. 4. Electrophoretic mobility shift of aldA promoter DNA fragment $f 5$ by extracts of strain ECL1 grown aerobically on rhamnose (a). The effect of the addition of the inducers glycolaldehyde and 2-oxoglutarate to extracts of strain ECL1 grown aerobically on rhamnose or glucose is also presented (b). Free (D), regulator-bound (R), regulator-bound in the presence of glycolaldehyde (G) and RNA-polymerase-bound (N) bands after autoradiography are indicated. The composition of the binding reaction run in every lane is indicated at the base: $f 5^{*}, 10 \mathrm{fmol}$ labelled fragment $\mathrm{f5}$; $\mathrm{f5}$, $20 \mathrm{ng}$ unlabelled fragment 5; poly(dl-dC), $2 \mu \mathrm{g}$ unlabelled synthetic oligonucleotide; extract (Rha), 1 or $2 \mu \mathrm{g}$, as indicated, crude protein extract of cells grown aerobically on rhamnose; extract (Glu), $1 \mu \mathrm{g}$ crude protein extract of cells grown aerobically on glucose; and glycolaldehyde or 2-oxoglutarate, $50 \mathrm{mM}$ of these inducer molecules.

lac $Z$ gene to generate plasmids pRS550 $\Delta-35$, pRS550 $\Delta--119$ and pRS550 $\Delta-287$. As described in Methods, all fusions were assayed as single-copy lysogens in strain RYC1000 to avoid potential artifacts due to multiple copies of the fusions in each cell.

Cultures of the lysogens on rhamnose plus glucose medium were grown to exponential phase and then reinoculated into the same medium with or without $5 \mathrm{mM}$ cAMP. Samples were taken every hour to analyse the $\beta$-galactosidase activity. Fig. 5 shows that strain RYC1000:: $\lambda$ RS $\Delta-35$ displayed no activity while

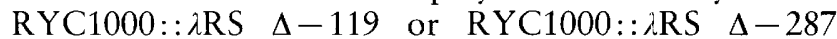
recovered high levels of $\beta$-galactosidase activity after 4-5 $\mathrm{h}$ incubation in the presence of cAMP, indicating that at least the Crp site between positions -47 to -74 was functional. Nevertheless, these activities were about half those obtained by growth on rhamnose (not shown), which is consistent with the previously described cAMPindependent catabolite repression (Quintillá et al., 1991).

The response to Crp of the tsp distal control site was further ruled out in favour of the proximal copy of the $\mathrm{Crp}$ sequence by gel retardation experiments with ${ }^{32} \mathrm{P}$ labelled fragments that contained either of the Crp-like boxes. It was demonstrated that the electrophoretic mobility of fragment $3(-111$ to -276$)$ was not affected by incubation with pure Crp in the presence of $20 \mu \mathrm{M}$
cAMP. Furthermore, a synthetic fragment $(-121$ to -150 ) with the distal Crp site was not retarded, indicating that it did not bind Crp-cAMP pure complex (not shown). In contrast, the electrophoretic mobility of fragment $2(-3$ to -184$)$ was significantly retarded by incubation with Crp-cAMP complex (Fig. 6, lane 2). Specificity of the sequence was ascertained by adding poly (dI-dC) (Fig. 6, lane 3) or unlabelled fragment 2 (Fig. 6, lane 6). Addition of pure RNA polymerase permitted the identification of the retarded band $(\mathrm{N})$ corresponding to the DNA-RNA polymerase complex formed with fragment 2 in the absence (Fig. 6, lane 4) or in the presence (Fig. 6, lane 5) of the Crp-cAMP complex.

The dissociation constant of the Crp-cAMP complex for fragment 2 was determined by incubating $0.5 \mathrm{ng}$ labelled fragment 2 with concentrations of Crp ranging from 0.2 to $1.6 \mu \mathrm{M}$ in the presence of $20 \mu \mathrm{M}$ cAMP. The intensity of retarded bands was measured by densitometry and plotted against the concentration of Crp present in the reaction mixture (Fig. 7). A $K_{d}$ of $5.4 \times 10^{-7} \mathrm{M}$ was determined in this way.

The region of the Crp binding was determined more precisely by DNase I protection. The 5'- and $3^{\prime}$-endlabelled Crp sequences were partially digested with DNase I in the presence or absence of Crp-cAMP complex and the digest was analysed by electrophoresis 


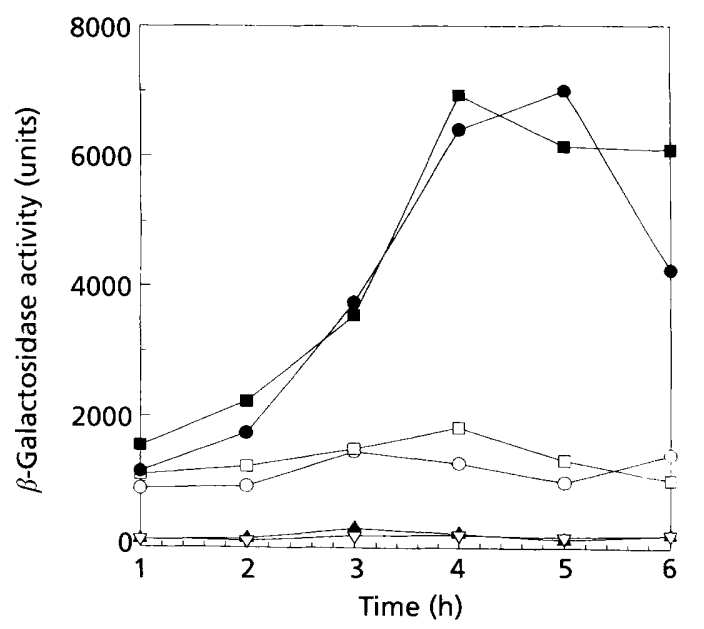

Fig. 5. Time-course of $\beta$-galactosidase activity of strains

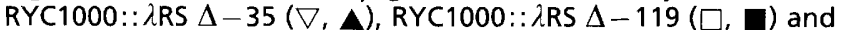
RYC1000:: $\lambda$ RS $\Delta-287(0,0)$ grown on rhamnose plus glucose in the absence (open symbols) or presence (filled symbols) of $5 \mathrm{mM}$ CAMP. A rhamnose plus glucose-grown inoculum was used to start $200 \mathrm{ml}$ of each of the three cultures, and $10 \mathrm{ml}$ samples were taken at $1 \mathrm{~h}$ intervals for determination of $\beta$ galactosidase activities.

together with the corresponding sequencing ladder (Fig. 8 ). In the sense strand, Crp protected from nucleotides -47 to -84 , whereas in the antisense strand the protection was from nucleotides -44 to -74 with an overlap going from position -47 to -74 , which included the consensus inverted repeat described by de Crombrugghe et al. (1984).

\section{Aerobic/anaerobic control of aldA gene expression by Arc}

The description of the ALDH encoded by aldA as a predominantly aerobic enzyme led us to study the control of its expression in the presence or absence of oxygen. Since a 10 -fold increase in enzyme activity was observed in response to oxygen availability, we examined whether the ArcA regulatory protein was involved in this control (Iuchi \& Lin, 1988). A strain containing a mutation in arcA (strain ECL968) as well as its parental strain (ECL547) were made lac-negative by mutagenesis with diethyl sulphate (Roth, 1970), and transformed with plasmid pRS550 $\Delta-287$ containing lacZ fused to the aldA promoter. These strains were analysed following aerobic or anaerobic growth on rhamnose minimal medium. The expression of the ald $A-l a c Z$ fusion in the $\operatorname{arc} A$ mutant strain grown under anaerobic conditions (18700 units of $\beta$-galactosidase activity) rose to the level of the wild-type parental strain, reaching the same level obtained in both strains under aerobic conditions (19375 units in the wild-type strain and 20750 units in the mutant strain). These findings suggest that ArcA acts as a negative regulator of ald A gene expression under anaerobiosis. The consensus for ArcA recognition, TGTTAATTAA, as determined by

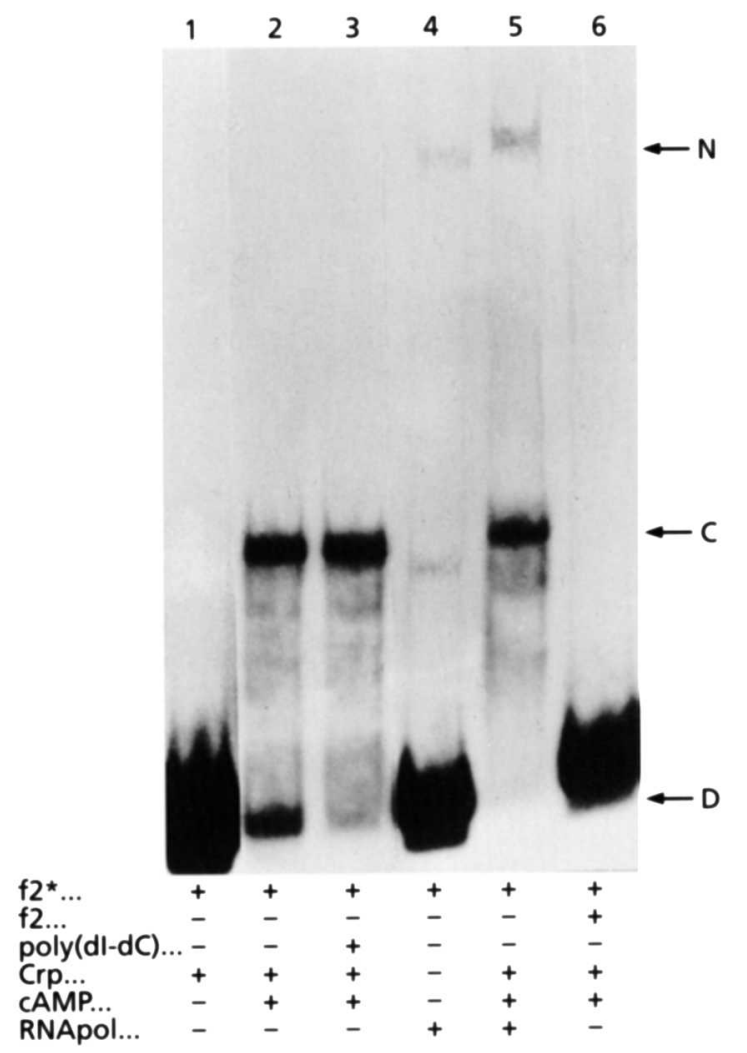

Fig. 6. Electrophoretic mobility shift of aldA promoter DNA fragment $f 2$ by Crp. Free (D), Crp-cAMP-bound (C) and RNApolymerase-bound $(\mathrm{N})$ bands after autoradiography are indicated. The composition of the binding reaction run in every lane is indicated at the base: $f 2^{*}, 10 \mathrm{fmol}$ labelled fragment $f 2$; $\mathrm{f} 2,20 \mathrm{ng}$ unlabelled fragment $\mathrm{f} 2$; poly(dl-dC), $2 \mu \mathrm{g}$ unlabelled synthetic oligonucleotide; Crp, 20 pmol pure Crp; CAMP, $400 \mathrm{pmol}$ CAMP; and RNApol, $500 \mathrm{fmol}$ pure RNA polymerase.

Lynch \& Lin (1996), was indeed found between positions -13 and -4 of the ald $A$ promoter with a conservation of $10 / 10$ nucleotides.

\section{Binding of IHF to the aldA promoter}

The promoter sequence presented above displayed three copies of a rather conserved IHF recognition sequence (positions 7 to $-6,-55$ to -67 and -130 to -142 ). Binding of the IHF, formed by himA and hip (himD) gene products, to these sequences was studied by gel retardation experiments with ${ }^{32} \mathrm{P}$-labelled fragments 1,2 or 3 containing the IHF recognition sequences (Fig. 1). Electrophoretic mobility of any of the three fragments was significantly retarded after incubation with 100, 50 or $30 \mathrm{ng}$ IHF purified protein (not shown). Specificity of the sequence was ascertained by adding the nonspecific competitor poly $(\mathrm{dI}-\mathrm{dC})$ or the specific competitor unlabelled fragment. However, a $\operatorname{bim} A$ mutant (strain HN1491) and a hip (himD) mutant (strain K2704), previously made lac-negative by mutagenesis with diethyl sulfate (Roth, 1970) and transformed with plasmid pRS550 $\Delta-287$ containing the aldA-lacZ fusion, had no significant effect on ald $A$ expression. 

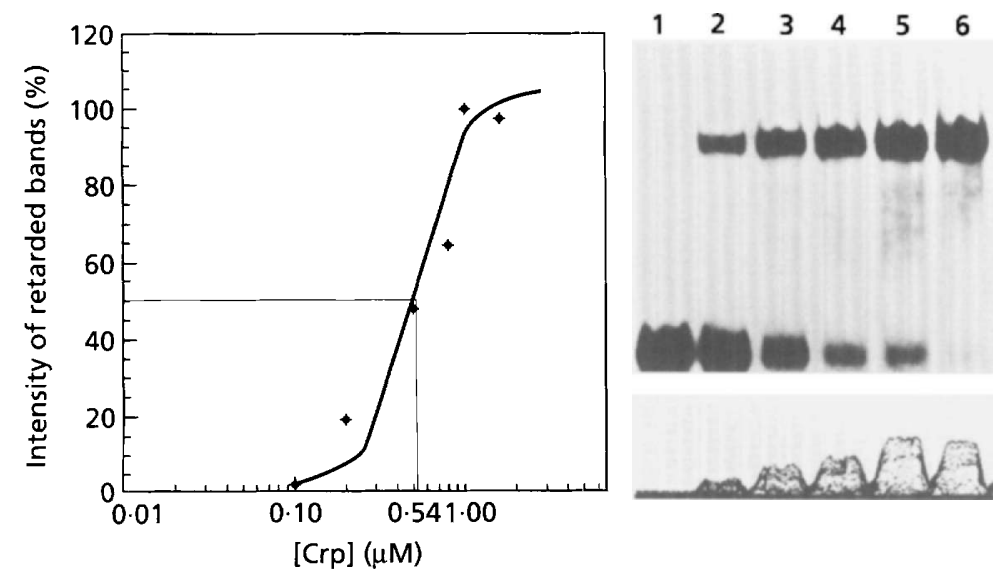

Fig. 7. Determination of the $K_{\mathrm{d}}$ for the ald promoter binding by Crp. Band shift assays shown on the right were performed with ${ }^{32}$ P-labelled fragment 2 incubated in the presence of $0.1,0.2,0.5,0.8,1.0$ and $1.6 \mu \mathrm{M}$ Crp and $20 \mu \mathrm{M}$ CAMP (lanes 1-6). The gel was analysed by scanning densitometry with a Vilbert-Lourmat system. The values obtained are expressed as per cent of maximum DNA-Crp binding, and are plotted against increasing concentrations of Crp.
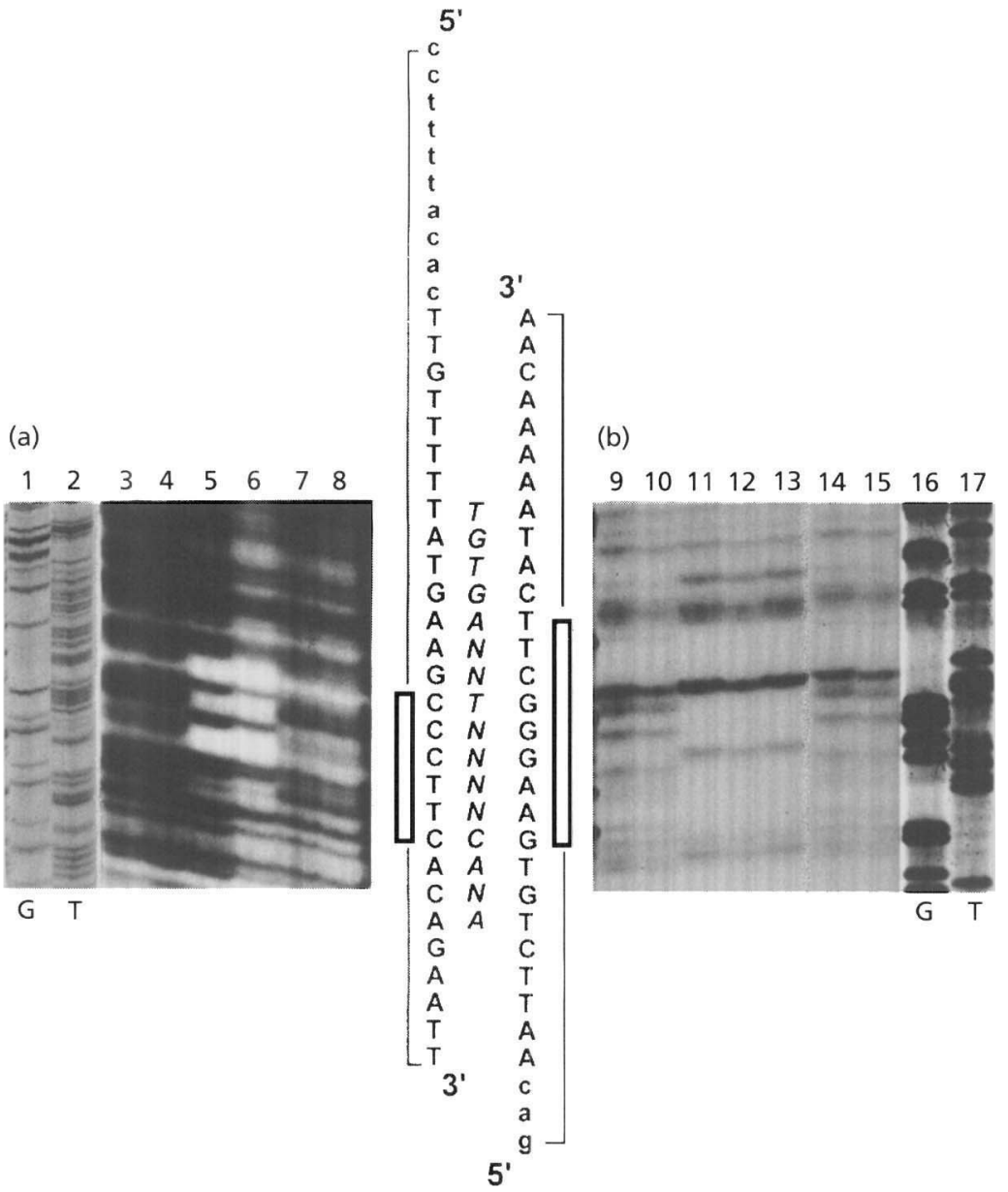

Fig. 8. DNase I footprint of the CAMP-Crp protein complex of the aldA promoter region. Panels correspond to the autoradiographs of the sequencing gels loaded with the products of the digestion and show the DNase I protection patterns of sense (a) and antisense (b) strands of fragment $f 2$. Lanes $3,4,7$ and 8 in (a) and 9, 10,14 and 15 in (b) are the result of the digestion in the absence of Crp. Lanes 5 and 6 in (a) and 11, 12 and 13 in (b) are the result of the digestion in the presence of $0.83 \mu \mathrm{M} C r p$ and $20 \mu \mathrm{M}$ cAMP. Lanes 1 and 2 in (a) and 16 and 17 in (b) correspond to $G$ and $T$ sequencing ladder, respectively. In the centre, the extent of each footprinting is indicated by open bars, the sequences protected are shown in upper case letters, and between them the Crp consensus described by de Crombrugghe et al. (1984) is aligned.

\section{DISCUSSION}

It is well established that the ALDH encoded by the ald $A$ gene oxidizes different hydroxyaldehydes and serves several metabolic pathways (Baldomà \& Aguilar, 1987).
The wide spectrum of catalytic activity and metabolic function is not uncommon to most ALDHs and is probably the cause of the requirement for multiple regulatory mechanisms. These include: (i) at least two regulatory mechanisms for two classes of inducer 
molecules sharing a common regulator protein; (ii) a cAMP-dependent and a cAMP-independent catabolite repression; and (iii) an aerobic control by the $\mathrm{ArcAB}$ regulatory system. It is not clear whether IHF regulates ald $A$ expression.

Two inducing mechanisms are proposed on the basis of the following observations. Full induction by rhamnose, hence by aldehydes such as lactaldehyde, required sequences of the promoter up to -170 , whereas full induction by casein acid hydrolysate, hence by 2 oxoglutarate, required only sequences up to -93 . This is in accordance with two DNA-regulator interactions that could be mediated by one or two regulator proteins. Previous characterization of induction of ald $A$ by different inducers suggested a single regulator model for which the two kinds of inducer would compete (Quintillá et al., 1991).

Our results reveal the constitutive presence of regulator protein in the extracts and its ability to bind the proximal promoter when the inducer is complexed either in vivo or in vitro. The results are consistent with a higher affinity of the regulator-inducer complex for DNA when the inducer is 2-oxoglutarate instead of glycolaldehyde.

Band shift assays confirmed that the tsp proximal operator overlaps with the RNA polymerase binding site, a situation common for repressor controls but not for activator controls like the one found in the ald $A$ gene. In these and other cases, RNA polymerase binding for transcription initiation is synergistic with the binding of other factors such as regulator proteins or Crp (Adhya et al., 1993). It has been proposed that these factors may contribute to the formation of an RNA polymerase open complex in promoters with weak -10 and -35 sequences, as exemplified by the galactose operon promoter (Chan et al., 1990), or with abnormal distances between the two boxes (Hidalgo \& Demple, 1994; Summers, 1992). In this context, it has also been proposed by Kumar et al. (1994) that formation of the RNA polymerase complex, in the absence of the -35 box, might be facilitated by the extended -10 hexamer found in these weak promoters.

The interaction with the distal sequences required for full induction by aldehydes (growth on rhamnose) is not understood. It is likely that interactions with the distal regulatory site, centred at -134 , could play a role, especially taking into account the requirement of sequences upstream of position -119 for full induction. This could be mediated either by interactions with another protein regulator factor or by induced conformational changes of the promoter DNA. In this context, bending of DNA by Crp interaction, as described for other systems such as the gal promoter (Lavigne et al., 1992), may influence the mechanism of transcription initiation. Furthermore, curved sequences could also account for uncharacterized regulatory effects (decrease in induction) caused by the presence of sequences upstream of position -193 (Fig. 3). The cooperation of this distal upstream regulatory site for induction would be competed for by the cAMPindependent repressor formed in the presence of glycerol (Fig. 3). Absolute requirement of the proximal Crp site, centred at -60 , for induction by either of the two types of inducer molecule would explain total repression by glucose under all conditions.

Catabolite repression of ald $A$ expression has been welldocumented in studies of enzyme levels under different physiological conditions. Here the repression at the transcriptional level is confirmed by the use of lac $Z$ fusions to the ald $A$ promoter. Our promoter deletion analysis, mobility shift assays and DNase protection assays seem to rule out the upstream control site centred at -134 as a Crp site and confirm the function of the Crp site centred at -60 . At this site, the DNase-Iprotected sequences of each strand displayed an overlap of 28 nucleotides, which included the Crp consensus described by de Crombrugghe $e t$ al. (1984), with nine of the ten nucleotides of the palindrome identical and a common six nucleotide spacer. Affinity of Crp for this site was one order of magnitude lower than other examples described in the literature (Barber et al., 1993). However, several Crp-dependent promoters have a $K_{\mathrm{d}}$ value similar to the one described here for ald A (Kolb et al., 1993).

The inability to restore full expression in the presence of cAMP in the fusion experiments with the complete promoter is in accordance with the presence of a cAMPindependent catabolite repression, as described by Ullmann et al. (1976) and revised by Kolb et al. (1993).

Another level of control of aldA expression is suggested by the absolute oxygen requirement for ALDH activity. No enzyme is detected by catalytic activity or immunodetection under anaerobic conditions (Baldomà \& Aguilar, 1988). Arc regulatory protein seems to supply such a control, as indicated by the anaerobic increase in $\beta$-galactosidase activity in ald A promoter-lac $Z$ fusion strains defective for Arc function and hence unable to repress under anaerobiosis.

Three IHF sites were found in the ald $A$ promoter which, according to DNA mobility shift experiments, bind pure IHF regulatory protein. No significant effect of IHF on ald $A$ expression was detected under our conditions, although the possibility of its widely accepted role as stabilizer of DNA conformation remains open (Nash \& Granston, 1991). The large number of IHF-binding sites spread over the E. coli genome, the lack of many strong phenotypes associated with gene expression in IHF mutants (Friedman, 1988) and the ability of IHF to bend and compact DNA (Schmid, 1990) are all consistent with this hypothesis.

\section{ACKNOWLEDGEMENTS}

We thank S. Adhya and H. A. Nash for purified proteins, M. Aldea and E. C. C. Lin for bacterial strains and R. Rycroft for editorial assistance. This work was supported by grant PB940829 from the Dirección General de Investigación Científica y Técnica, Madrid, Spain, and by the help of the "Comissionat 
per Universitats i recerca de la Generalitat de Catalunya'. A. L. was the recipient of a predoctoral fellowship (FPI) from the Ministerio de Educacion y Ciencia of Spain.

\section{REFERENCES}

Adhya, S., Gottesman, M., Garges, S. \& Oppenheim, A. (1993). Promoter resurrection by activators - a minireview. Gene 132, 1-6.

Baldomà, L. \& Aguilar, J. (1987). Involvement of lactaldehyde dehydrogenase in several metabolic pathways of Escherichia coli K-12. J Biol Chem 262, 13991-13996.

Baldomà, L. \& Aguilar, J. (1988). Metabolism of L-fucose and Lrh:amnose in Escherichia coli: aerobic regulation of L-lactaldehyde dissimilation. J Bacteriol 170, 416-421.

Barber, A. M., Zhurkin, V. B. \& Adhya, S. (1993). CRP-binding sites: evidence for two structural classes with 6-bp and 8-bp spacers. Gene 130, 1-8.

Belasco, J. G., Beatty, T., Adams, C. W., von Gabain, A. \& Cohen, S. N. (1985). Differential expression of photosynthesis genes in $R$. capsulata results from segmental differences in stability within the polycistronic $r x c$ A transcript. Cell 40, 171-181.

Boronat, A. \& Aguilar, J. (1979). Rhamnose-induced propanediol oxidoreductase in Escherichia coli: purification, properties, and comparison with the fucose-induced enzyme. J Bacteriol 140 , $320-326$.

Boronat, A. \& Aguilar, J. (1981). Metabolism of L-fucose and Lrhamnose in Escherichia coli: differences in induction of propanediol oxidoreductase. J Bacteriol 147, 181-185.

Boronat, A., Caballero, E. \& Aguilar, J. (1983). Experimental evolution of a metabolic pathway for ethylene glycol utilization by Escherichia coli. J Bacteriol 153, 134-139.

Caballero, E., Baldomà, L., Ros, J., Boronat, A. \& Aguilar, J. (1983). Identification of lactaldehyde dehydrogenase and glycolaldehyde dehydrogenase as functions of the same protein in Escherichia coli. J Biol Chem 258, 7788-7792.

Chan, B., Spassky, A. \& Busby, S. (1990). The organization of open complexes between Escherichia coli RNA polymerase and DNA fragments carrying promoters either with or without consensus -35 region sequences. Biochem J 270, 141-148.

Chen, Y. M., Zhu, Y. \& Lin, E. C. C. (1987). NAD-linked aldehyde dehydrogenase for aerobic utilization of $\mathrm{L}$-fucose and $\mathrm{L}$-rhamnose by Escherichia coli. J Bacteriol 169, 3289-3294.

Cocks, G. T., Aguilar, J. \& Lin, E. C. C. (1974). Evolution of the 1,2propanediol catabolism in Escherichia coli by recruitment of enzymes for L-fucose and L-lactate metabolism. J Bacteriol 118, 83-88.

de Crombrugghe, B., Busby, S. \& Buc, H. (1984). Cyclic AMP receptor protein: role in transcription activation. Science 224, 831-838.

Friedman, D. I. (1988). Integration host factor: a protein for all reasons. Cell 55, 545-554.

Granston, B. E. \& Nash, H. A. (1993). Characterization of a set of integration host factor mutants deficient for DNA binding. $J \mathrm{Mol}$ Biol 234, 45-59.

Hidalgo, E. \& Demple, B. (1994). An iron-sulfur center essential for transcriptional activation by redox-sensing Sox R protein. EMBO $J 13,138-146$.

Hidalgo, E., Chen, Y. M., Lin, E. C. C. \& Aguilar, J. (1991). Molecular cloning and DNA sequencing of the gene ald encoding lactaldehyde dehydrogenase from Escherichia coli. J Bacteriol $173,6118-6123$.
Holmes, D. S. \& Quigley, M. (1981). A rapid boiling method for the preparation of bacterial plasmids. Anal Biochem 114, 193-197. luchi, S. \& Lin, E. C. C. (1988). ArcA (dye), a global regulatory gene in Escherichia coli mediating repression of enzymes in anaerobic pathways. Proc Natl Acad Sci USA 85, 1888-1892.

luchi, S. \& Lin, E. C. C. (1992). Mutational analysis of signal transduction by $\mathrm{ArcB}$, a membrane sensor protein responsible for anaerobic repression of operons involved in the central aerobic pathways of Escherichia coli. J Bacteriol 174, 3972-3980.

Kolb, A., Busby, S., Buc, H., Garges, S. \& Adhya, S. (1993). Transcriptional regulation by cAMP and its receptor protein. Annu Rev Biochem 62, 749-795.

Kumar, A., Grimes, B., Fugita, N., Makino, R., Malloch, A., Hayward, R. S. \& Ishihama, A. (1994). Role of the $\sigma^{70}$ subunit of Escherichia coli RNA-polymerase in transcription activation. J Mol Biol 235, 405-413.

Lavigne, M., Herbert, M., Kolb, A. \& Buc, H. (1992). Upstream curved sequences influence the initiation of transcription at the Escherichia coli galactose operon. J Mol Biol 224, 293-306.

LeBlanc, D. \& Mortlock, R. P. (1971). Metabolism of D-arabinose: a new pathway in Escherichia coli. J Bacteriol 106, 90-96.

Lin, E. C. C. (1976). Glycerol dissimilation and its regulation in bacteria. Annu Rev Microbiol 80, 535-578.

Lynch, A. S. \& Lin, E. C. C. (1996). Transcriptional control mediated by the ArcA two-component response regulator protein of Escherichia coli: characterization of DNA binding at target promoters. J Bacteriol 178, 6238-6249.

Meissner, P. S., Sisk, W. P. \& Berman, M. L. (1987). Bacteriophage $\lambda$ cloning system for the construction of directional $\mathrm{CDNA}$ libraries. Proc Natl Acad Sci USA 84, 4171-4178.

Miller, J. H. (1992). A Short Course in Bacterial Genetics. Cold Spring Harbor, NY : Cold Spring Harbor Laboratory.

Moralejo, P., Egan, S. M., Hidalgo, E. \& Aguilar, J. (1993). Sequencing and characterization of a gene cluster encoding the enzymes for L-rhamnose metabolism in Escherichia coli. J Bacteriol 175, 5585-5594.

Mozola, M. A. \& Friedman, D. I. (1985). A phi 80 function inhibitory for growth of lambdoid phage in bim mutants of Escherichia coli deficient in IHF. Genetic analysis of the Rha phenotype. J Virol 140, 313-327.

Nash, H. A. \& Granston, A. E. (1991). Similarity between the DNA binding domains of IHF protein and TFIID protein. Cell 67, 1037-1038.

Nunoshiba, T., Hidalgo, E., Amabile-Cuevas, C. F. \& Demple, B. (1992). Two stage control of an oxidative stress regulon: the Escherichia coli SoxR protein triggers redox-inducible expression of the soxS regulatory gene. J Bacteriol 174, 6054-6060.

Quintillá, F. X., Baldomà, L., Badra, J. \& Aguilar, J. (1991). Aldehyde dehydrogenase induction by glutamate in Escherichia coli. Role of 2-oxoglutarate. Eur J Biochem 202, 1321-1325.

Roth, J. (1970). Genetic techniques in studies of bacterial metabolism. Methods Enzymol 17, 1-35.

Sambrook, J., Fritsch, E. F. \& Maniatis, T. (1989). Molecular Cloning: a Laboratory Manual, 2nd edn. Cold Spring Harbor, NY: Cold Spring Harbor Laboratory.

Sanger, F., Nicklen, S. \& Coulson, A. R. (1977). DNA sequencing with chain terminating inhibitors. Proc Natl Acad Sci USA 74, $5463-5467$.

Schmid, M. B. (1990). More than just 'histone-like' proteins. Cell 63, 451-453.

Simons, R. W., Houman, F. \& Kleckner, N. (1987). Improved single 
and multicopy lac-based cloning vectors for protein and operon fusions. Gene 53, 85-96.

Sridhara, S. \& Wu, T. T. (1969). Purification and properties of lactaldehyde dehydrogenase from Escherichia coli. J Biol Chem 244, 5233-5238.

Summers, A. O. (1992). Untwist and shout: a heavy metalresponsive transcriptional regulator. J Bacteriol 174, 3097-3101.

Ullmann, A., Tillier, F. \& Monod, J. (1976). Catabolite modulator factor: a possible mediator of catabolite repression in bacteria. Proc Natl Acad Sci USA 73, 3476-3479.

Wu, Y. \& Datta, P. (1992). Integration host factor is required for positive regulation of the $t d c$ operon of Escherichia coli. J Bacteriol 174, 233-240.

Received 28 October 1996; revised 3 February 1997; accepted 7 February 1997. 